\title{
Frequency of anaplastic lymphoma kinase rearrangements in Moroccan patients with non small cell lung cancer: a multi- institutional national retrospective study
}

Hind El yacoubi ${ }^{1,2,3^{*}}$ (D) Mohamed Lemine Sow ${ }^{3}$, Fouad Kettani ${ }^{4}$, Lamia Gamra ${ }^{5}$, Amina Mestari ${ }^{6}$, Lamia Jabri ${ }^{7}$, Ibrahim Elghissassi ${ }^{1,3}$ and Hassan Errihani ${ }^{1,3}$

\begin{abstract}
Background: Anaplastic lymphoma kinase (ALK) rearrangement is a predictive factor of response to ALK inhibitors in non small cell lung cancer (NSCLC). The prevalence of ALK rearrangements is well known in Whites and Asians. However, data identifying the frequency of this rearrangement in Moroccan and North African population are lacking. The objective of this study is to report the frequency of ALK rearrangement in a group of Moroccan patients with NSCLC.

Methods: A retrospective study was performed enrolling 120 Moroccan patients with NSCLC whose biopsy samples were tested for ALK rearrangement in order to identify the frequency of ALK rearrangement and its potential association with selected variables. The ALK testing was established using fluorescent in situ hybridization (FISH) or immunohistochemistry (IHC).

Results: The frequency of ALK rearrangement was 4.2\% (5/120). All positive cases were males with advanced adenocarcinoma. ALK rearrangements prevalence was significantly higher in older patients.

Conclusions: The frequency of ALK rearrangements among the Moroccan population tends to correlate with the average frequency reported worldwide, with some specific features. Further prospective studies with larger patients' numbers are needed to verify these findings.
\end{abstract}

Keywords: Anaplastic lymphoma kinase rearrangement, Non small cell lung cancer, Morroco, Frequency

\section{Background}

Lung cancer is one of the most commonly diagnosed cancers in both sexes and the leading cause of cancer deaths worldwide [1]. Nevertheless, several advances have improved the management and treatment of non

\footnotetext{
* Correspondence: drhind@hotmail.fr

'Research and investigation in medical oncology Moroccan group, Faculty of medicine and pharmacy, Mohammed V University, Impasse souissi, 10100 Rabat, Morocco

2Department of Medical Oncology, Mohammed Bouafi Hospital, Casablanca, Morocco

Full list of author information is available at the end of the article
}

small cell lung cancer (NSCLC), mainly the discovery of specific oncogenic drivers that guide the choice of treatment towards the appropriate targeted therapy. Anaplastic lymphoma kinase (ALK) rearrangement was first documented in 2007 in NSCLC [2]. Echinoderm Microtubule associated protein Like 4 (EML4) gene is the most frequent ALK partner that have been described among various ALK fusion genes [3]. ALK-EML4 rearrangement is the consequence of a gene fusion in chromosome 2 between ALK gene and EML4 gene which leads to the activation of the tyrosine kinase domain of ALK protein that

(c) The Author(s). 2020 Open Access This article is licensed under a Creative Commons Attribution 4.0 International License, which permits use, sharing, adaptation, distribution and reproduction in any medium or format, as long as you give appropriate credit to the original author(s) and the source, provide a link to the Creative Commons licence, and indicate if changes were made. The images or other third party material in this article are included in the article's Creative Commons licence, unless indicated otherwise in a credit line to the material. If material is not included in the article's Creative Commons licence and your intended use is not permitted by statutory regulation or exceeds the permitted use, you will need to obtain permission directly from the copyright holder. To view a copy of this licence, visit http://creativecommons.org/licenses/by/4.0/ The Creative Commons Public Domain Dedication waiver (http://creativecommons.org/publicdomain/zero/1.0/) applies to the data made available in this article, unless otherwise stated in a credit line to the data. 
enhances tumor growth and proliferation [2]. Thus, targeting this tumorigenesis pathway has improved the survival and clinical outcomes of this subset of patients harboring ALK rearrangements by using ALK inhibitors $[4,5]$. However, ALK rearrangements occur in 2 to $7 \%$ of all NSCLC and this frequency may vary by race, gender, histology type, and smoking habits [6-8]. These literature data are based on studies in Whites and Asians, the epidemiology of ALK rearrangements remains, nevertheless, less known in North African population.

The aim of this study is to report the frequency of ALK rearrangements in a group of Moroccan patients with NSCLC. Moreover, the study investigates the potential associations between ALK rearrangement status and selected variables.

\section{Methods}

A retrospective study was performed enrolling all NSCLC cases whose biopsy samples were tested for ALK rearrangement status between January 2014 and December 2017, from four pathology centers in Morocco.

The histopathology diagnosis was confirmed in local laboratories, then the formalin-fixed paraffin embedded tumor tissues were sent to France to test the ALK rearrangement using fluorescent in situ hybridization (FISH) or immunohistochemistry (IHC). The FISH analyses were performed in Biomnis medical biology laboratory in Lyon using LSI ALK 2p23 Dual Color, Break Apart Rearrangement Probe (Abott-Vysis). One hundred nuclei have to be counted to detect ALK rearrangements. The Tumor tissues were considered ALK FISHpositive if more than $15 \%$ of tumor cells are ALK rearranged. Otherwise the samples were considered as ALK FISH-negative. The IHC analyses were performed in the genetic laboratory of tumors at the Rouen university hospital using the antibody D5F3 clon (Roche-Ventana). IHC staining scores were assessed as follows: 0 , (no staining); 1+ (faint cytoplasmic staining); 2+ (moderate cytoplasmic staining); and 3+ (intense granular cytoplasmic staining). IHC score 0 defined negative ALK rearrangements. Tumor tissues scored $3+$ were considered as positive ALK rearrangements. IHC scores $1+$ and 2+ were considered as equivocal cases. The confirmation of ALK status was based on FISH results or IHC scores 0 and 3 , only equivocal cases had to be reevaluate by FISH, as per institutional and national policy and guidelines for ALK testing.

Genetic analysis of epidermal growth factor receptor (EGFR) and Kirsten rat sarcoma (Kras) gene mutations was performed using polymerase chain reaction assay and direct sequencing of exons 18,19, 20, and 21of the EGFR gene and exon 2 of Kras gene.

The study included only Moroccan patients with advanced NSCLC. All ALK tests obtained from the participating pathology labs were included. Information about age, gender, smoking history, histopathology type, ALK rearrangement status, EGFR and Kras mutations were collected. Patients who had smoked $<100$ cigarettes in their lifetime were defined as non-smokers and all others as smokers.

The data were described using standard descriptive statistical methods. Fisher's exact test was used to analyze the potential combinations of ALK rearrangement with gender, smoking status, histopathology type, the ALK test method performed, and EGFR and Kras status. The $t$ test was used to compare age means. A $p$ value less than 0.05 was considered statistically significant. The Statistical Package for the Social Sciences (SPSS) (version 20; SPSS Inc., Chicago, IL) was used to perform all the analyses.

\section{Results}

One hundred twenty Moroccan patients with confirmed NSCLC were included. All tumor specimens were tested for ALK rearrangement. Ninety-two patients were males (76.7\%), and twenty-eight were females (23.3\%). The median age was 63 (range, 28-88) years. 87.5\% presented with adenocarcinoma histology and $12.5 \%$ a mixed histology showing a partial adenocarcinoma differentiation, thus eligible for ALK testing. The ALK rearrangement test was performed mostly using FISH method (75\%) as it is the gold standard of ALK testing. $90 \%$ of IHC tests carried out were conclusive (24 score 0,3 score $3+$ ). Three cases were equivocal and ALK FISH-negative. The baseline characteristics of the study population are summarized in Table 1.

ALK rearrangement was found in 5 cases $(4.2 \%)$ of the 120 patients included. All ALK positive patients were males with adenocarcinoma histology. Three were nonsmokers and two were smokers. The ALK rearrangement was established using FISH in two cases and IHC in three cases (score 3+) (Table 2).

The mean age of patients harboring positive ALK rearrangements was found to be higher than that of patients having negative ALK rearrangement, a difference which was statistically significant (67.8 versus $63.3 p<0.0001)$. There was no difference in the incidence of ALK rearrangement between males and females, smokers and non-smokers. No concomitant ALK, EGFR or Kras mutations were found. EGFR and Kras status did not influence the incidence of ALK rearrangement (Table 3).

\section{Discussion}

Lung cancer is one of the most diagnosed cancers and the first cause of mortality related to cancer in both sexes [1]. Although important progress has been made in NSCLC molecular typing and personalized targeted 
Table 1 Demographic Characteristics of the study population

\begin{tabular}{|c|c|}
\hline Characteristics & All patients $(n=120) \mathrm{N}(\%)$ \\
\hline \multicolumn{2}{|l|}{ Age (yr) } \\
\hline Median & 63 \\
\hline Range & $28-88$ \\
\hline \multicolumn{2}{|l|}{ Gender } \\
\hline Male & $92(76.7 \%)$ \\
\hline Female & $28(23.3 \%)$ \\
\hline \multicolumn{2}{|l|}{ Smoking status } \\
\hline Smoker & $68(56.7 \%)$ \\
\hline Non-smoker & $52(43.3 \%)$ \\
\hline \multicolumn{2}{|l|}{ Histology } \\
\hline Adenocarcinoma & $105(87.5 \%)$ \\
\hline Others NSCLC & $15(12.5 \%)$ \\
\hline \multicolumn{2}{|l|}{ Stage } \\
\hline IV & $120(100 \%)$ \\
\hline \multicolumn{2}{|l|}{ ALK test } \\
\hline FISH & $90(75 \%)$ \\
\hline $\mathrm{IHC}$ & $30(25 \%)$ \\
\hline \multicolumn{2}{|l|}{ EGFR status } \\
\hline Mutated & $21(17.5 \%)$ \\
\hline Wild & 99 (82.5\%) \\
\hline \multicolumn{2}{|l|}{ Kras status } \\
\hline Mutated & $7(5.8 \%)$ \\
\hline Wild & $55(45.8 \%)$ \\
\hline Not tested & $58(48.3 \%)$ \\
\hline
\end{tabular}

Yr year, NSCLC non small cell lung cancer, ALK anaplastic lymphoma kinase, FISH fluorescent in situ hybridization, IHC immunohistochemistry, EGFR epidermal growth factor receptor, Kras Kirsten rat sarcoma

therapies which has contributed to better clinical outcomes. The use of ALK inhibitors in patients with NSCLC harboring ALK rearrangement demonstrated impressive response rate and progression free survival compared to chemotherapy $[4,5]$. Indeed the determination of ALK rearrangement status is a decisive factor of treatment and prognosis in NSCLC.

In our series ALK rearrangement was present in 5 of 120 Moroccan patients $(4.2 \%)$. The present study is - to our knowledge- the first to report the ALK
Table 3 Patient Characteristics by ALK Rearrangement Status

\begin{tabular}{|c|c|c|c|}
\hline \multirow[t]{2}{*}{ Characteristics } & \multicolumn{2}{|c|}{ ALK Rearrangement Status N(\%) } & \multirow[t]{2}{*}{ P } \\
\hline & Negative & Positive & \\
\hline Total & $115(95.8 \%)$ & $5(4.2 \%)$ & \\
\hline Mean age at diagnosis (yr) & 63.3 & 67.8 & $<0.0001^{*}$ \\
\hline Gender & & & $0.58^{* *}$ \\
\hline Male & $87(75.7 \%)$ & $5(100 \%)$ & \\
\hline Female & $28(24.3 \%)$ & $0(0 \%)$ & \\
\hline Smoking history & & & $0.65^{* *}$ \\
\hline Smoker & $66(57.4 \%)$ & $2(40 \%)$ & \\
\hline Non-smoker & $49(42.6 \%)$ & $3(60 \%)$ & \\
\hline Histological type & & & $0.50^{* *}$ \\
\hline Adenocarcinoma & $100(87 \%)$ & $5(100 \%)$ & \\
\hline Others & $15(13 \%)$ & $0(0 \%)$ & \\
\hline ALK test & & & $0.09^{* *}$ \\
\hline FISH & $88(76.5 \%)$ & $2(40 \%)$ & \\
\hline $\mathrm{IHC}$ & $27(23.5 \%)$ & $3(60 \%)$ & \\
\hline EGFR status & & & $0.58^{* *}$ \\
\hline Mutated & $21(100 \%)$ & $0(0 \%)$ & \\
\hline Wild & 94 (94.9\%) & $5(5.1 \%)$ & \\
\hline Kras status & & & $0.69^{* *}$ \\
\hline Mutated & $7(100 \%)$ & $0(0 \%)$ & \\
\hline Wild & $52(94.5 \%)$ & $3(5.5 \%)$ & \\
\hline
\end{tabular}

${ }^{*} p$ value calculated by $t$ test

** $p$ value calculated by Fisher's exact test

$A L K$ anaplastic lymphoma kinase, FISH fluorescent in situ hybridization, $I H C$ immunohistochemistry, EGFR epidermal growth factor receptor, Kras Kirsten rat sarcoma

rearrangement frequency in Moroccan population and the largest in North Africa.

The frequency that we found falls globally between the frequencies reported in whites and those reported in Asians [9-14]. However, it's lower than the frequency found in two previous Tunisian studies that reported an ALK rearrangement frequency of 5.2 and $9.09 \%$, respectively $[15,16]$ (Table 4$)$.

Furthermore, previous studies found similar overall distributions of ALK rearrangements according to race, and showed that ALK rearrangement onset on NSCLC patients was less influenced by ethnicity $[13,14]$.

Table 2 Data of Patients with ALK Positive Rearrangement

\begin{tabular}{|c|c|c|c|c|c|}
\hline Patients & Age-ranges & Gender & Smoking Status & Histology & ALK test \\
\hline 1 & $66-70$ & M & Smoker & Adenocarcinoma & $\mathrm{FISH}$ \\
\hline 2 & & M & Non-smoker & Adenocarcinoma & FISH \\
\hline 3 & & M & Smoker & Adenocarcinoma & $\mathrm{IHC}$ \\
\hline 4 & & M & Non-smoker & Adenocarcinoma & $\mathrm{IHC}$ \\
\hline 5 & & M & Non-smoker & Adenocarcinoma & $\mathrm{IHC}$ \\
\hline
\end{tabular}


Table 4 Frequency of ALK rearrangement by race

\begin{tabular}{lll}
\hline Study & Race & ALK rearrangement (\%) \\
\hline Zhou et al. [9] & East Asians (China) & 28/488 (5.7\%) \\
Soda et al. [10] & East Asians (Japan) & $32 / 754(4.24 \%)$ \\
Jin et al. [11] & East Asians (Korea) & $10 / 167(6 \%)$ \\
Martinez et al. [12] & Whites (Spain) & $7 / 99(7.1 \%)$ \\
Yamaguchi et al. [13] & Whites (USA) & $15 / 192(7.81)$ \\
Desai et al. [14] & South Asians (India) & $5 / 187(2.7 \%)$ \\
Arfaoui et al. [15] & North Africans (Tunisia) & $1 / 19(5.2 \%)$ \\
Toumi et al. [16] & North Africans (Tunisia) & $2 / 22(9.09 \%)$ \\
This study & North Africans (Morocco) & $5 / 120(4.2 \%)$ \\
\hline
\end{tabular}

$A L K$ anaplastic lymphoma kinase

Fan et al. [6] reported in their meta-analysis that patients with ALK rearrangements were younger than those without, in both Asians and Whites. In our series we observed that Moroccan patients with ALK positive were older than those with ALK negative, the mean age was 67.8 and 63.3 years old respectively $(p<0.0001)$. However, our findings are based on limited number of patients as compared to large published studies so we are unable to conclude in a real discordance with most available literature about age and ALK status $[2,6,7]$.

On the whole, data in the literature about the relationship between sex and NSCLC ALK status are heterogeneous. Zhou et al. [9] reported a higher rate of ALK positive in female in an East Asian population, while Shaw et al. [7] found more ALK positive in males than females. Besides, the meta-analysis by Fan et al. [6] didn't demonstrate a significant difference in ALK occurrence according to sex in a Western population, whereas Asian population presented more ALK positive in females than males. In the present study all ALK positive patients were males, without significant statistical difference according to patient's sex, which is likely due to the fact that males outnumber females in our study group (76.7\% versus $23.3 \%$, respectively).

Several studies have shown that NSCLC patients harboring ALK rearrangement were more likely to be never smokers compared to negative ALK patients [6, 7, 9]. Chapman et al. [8] also confirmed in their meta-analysis that ALK rearrangements occurred more in never smokers than ever smoker in both Asian and White patients with NSCLC. Our present study reported more non-smokers in ALK positive patients (60\%) but did not find a significant influence of smoking status on ALK positive frequency in Moroccan NSCLC patients, a result which is inconsistent with the majority of reports in the literature [6-9].

Histologically, previous studies reported more ALK fusions in patients with lung adenocarcinoma [5, 7, 8]. Fan et al. [6] found an association race dependent between lung cancer histology and ALK rearrangements. They identified a significantly higher proportion of ALK fusions in lung adenocarcinoma in Asians compared to Whites. In our group of Moroccan patients, among 120 included cases, 105 presented an adenocarcinoma. There was no relationship between the histological type and ALK status, a finding that tends to meet literature reports in White populations [6].

No coexistence of ALK rearrangement and EGFR or Kras mutations was detected in our series, a finding which is similar to widely reported mutually exclusive mutational pattern $[17,18]$. However, recent large studies report a higher frequency of the concomitance of ALK rearrangement in NSCLC patients, especially whose harboring EGFR mutations [19, 20].

Even though the ALK rearrangement could change according to patient's clinicopathological features, it is obvious that only positive ALK rearrangement is the predictive factor of clinical response to ALK inhibitors $[4,5]$. Our findings should be interpreted with caution since we were limited by the small number of patients, the retrospective enrollment and the lack of data about received treatments. Although, little data exists on the mapping of ALK rearrangements for NSCLC in North Africa, the present study helps to characterize this subset of NSCLC in our region and hopefully will be followed by prospective studies.

\section{Conclusions}

In summary, the present study found that the frequency of ALK rearrangement in Moroccan population with NSCLC goes along with the average frequency reported in unselected populations with NSCLC. In addition, older age might be a specific feature of Moroccan patients with ALK rearrangement. Further prospective studies with larger patient's numbers are needed to verify these findings.

\section{Abbreviations \\ ALK: Anaplastic lymphoma kinase; EML4: Echinoderm Microtubule associated protein Like 4; EGFR: Epidermal growth factor receptor; FISH: Fluorescent in situ hybridization; IHC: Immunohistochemistry; Kras: Kirsten rat sarcoma; NSCLC: Non small cell lung cancer}

\section{Acknowledgements \\ We thank Pr Hafida Chekeiri for her professional writing help.}

\section{Authors' contributions}

HE collected the data, performed the statistical analysis and wrote the manuscript. MLS participated in data collection. FK, LG, AM, and $L J$ performed the histological examination and participated in data collection. IE helped to draft the manuscript and reviewed the final version. HE validated content and form of the article. All authors read and approved the final manuscript.

Funding

This study was not funded by any external sources. 


\section{Availability of data and materials}

The datasets used and/or analyzed during the current study are available from the corresponding author on reasonable request.

\section{Ethics approval and consent to participate}

The ethics committee approval was not necessary for this study, since all ALK tests were part of the routine diagnostic procedure and all patient and tumor characteristics were collected anonymously.

\section{Consent for publication}

Not applicable.

\section{Competing interests}

The authors declare that they have no competing interests.

\section{Author details}

${ }^{1}$ Research and investigation in medical oncology Moroccan group, Faculty of medicine and pharmacy, Mohammed V University, Impasse souissi, 10100 Rabat, Morocco. ${ }^{2}$ Department of Medical Oncology, Mohammed Bouafi Hospital, Casablanca, Morocco. ${ }^{3}$ Department of Medical Oncology, National Institute of Oncology, Rabat, Morocco. ${ }^{4}$ Department of Pathology, Nations-Unies Pathology Center, Rabat, Morocco. ${ }^{5}$ Department of Pathology, Hassan Pathology Center, Rabat, Morocco. ${ }^{6}$ Department of Pathology, Agdal Pathology Center, Rabat, Morocco. ${ }^{7}$ Department of Pathology, Casapath Pathology Center, Casablanca, Morocco.

Received: 6 August 2019 Accepted: 18 May 2020

Published online: 27 May 2020

\section{References}

1. Bray F, Ferlay J, Soerjomataram I, et al. Global cancer statistics 2018: GLOBOCAN estimates of incidence and mortality worldwide for 36 cancers in 185 countries. CA Cancer J Clin. 2018;68(6):394-424.

2. Soda M, Choi YL, Enomoto M, et al. Identification of the transforming EML4ALK fusion gene in non-small-cell lung cancer. Nature. 2007;448:561-6.

3. Xue $D$, Yun $S$, Hai-Feng $Q$, et al. ALK-rearrangement in non-small-cell lung cancer (NSCLC). Thorac Cancer. 2018;9(4):423-30.

4. Solomon BJ, Kim DW, Wu YL, et al. Final overall survival analysis from a study comparing first-line Crizotinib versus chemotherapy in ALK-mutationpositive non-small-cell lung Cancer. J Clin Oncol. 2018;36:2251.

5. Solomon BJ, Mok T, Kim DW, et al. First-line crizotinib versus chemotherapy in ALK-positive lung cancer. N Engl J Med. 2014 Dec 4;371(23):2167-77.

6. Fan $\mathrm{L}$, Feng $Y$, Wan $\mathrm{H}$, et al. Clinicopathological and demographical characteristics of non-small cell lung cancer patients with ALK rearrangements: a systematic review and meta-analysis. PLoS One. 2014;9(6): e100866.

7. Shaw AT, Yeap BY, Mino-Kenudson M, et al. Clinical features and outcome of patients with non-small-cell lung cancer who harbor EML4-ALK. J Clin Oncol. 2009;27:4247.

8. Chapman AM, Sun KY, Ruestow P, et al. Lung cancer mutation profile of EGFR, ALK, and KRAS: meta-analysis and comparison of never and ever smokers. Lung Cancer. 2016;102:122-34.

9. Zhou JX, Yang H, Deng Q, et al. Oncogenic driver mutations in patients with non-small-cell lung cancer at various clinical stages. Ann Oncol. 2013; 24:1319-25.

10. Soda M, Isobe $\mathrm{K}$, Inoue A, et al. A prospective PCR-based screening for the EML4-ALK oncogene in non-small cell lung Cancer. Clin Cancer Res. 2012; 18(20):5682-9.

11. Jin G, Jeon HS, Lee EB, et al. EML4-ALK fusion gene in Korean non-small cell lung cancer. J Korean Med Sci. 2012;27:228-30

12. Martinez $\mathrm{P}$, Hernandez-Losa J, Montero MA, et al. Fluorescence in situ hybridization and immunohistochemistry as diagnostic methods for ALK positive non-small cell lung cancer patients. PLoS One. 2013;8(1):e52261.

13. Yamaguchi N, Vanderlaan PA, Folch E, et al. Smoking status and selfreported race affect the frequency of clinically relevant oncogenic alterations in non-small-cell lung cancers at a United States based academic medical practice. Lung Cancer. 2013 Oct;82(1):31-7.

14. Desai SS, Shah AS, Prabhash K, Jambhekar NA. A year of anaplastic large cell kinase testing for lung carcinoma: pathological and technical perspectives. Indian J Cancer. 2013;50(2):80-6.
15. Arfaoui AT, Blel A, Aloui R, et al. ALK protein expression in pulmonary adenocarcinoma of Tunisian patients. J Immunoassay Immunochem. 2017; 38(4):411-9.

16. Arfaoui Toumi A, Blel A, Aloui R, et al. Assessment of EGFR mutation status in Tunisian patients with pulmonary adenocarcinoma. Curr Res Transl Med. 2018;66(3):65-70.

17. Gainor JF, Varghese AM, Ou SH, et al. ALK rearrangements are mutually exclusive with mutations in EGFR or KRAS: an analysis of 1,683 patients with non-small cell lung cancer. Clin Cancer Res. 2013;19:4273-81.

18. Zhang $X$, Zhang S, Yang $X$, et al. Fusion of EML4 and ALK is associated with development of lung adenocarcinomas lacking EGFR and KRAS mutations and is correlated with ALK expression. Mol Cancer. 2010;9:188.

19. Hu W, Liu Y, Chen J. Concurrent gene alterations with EGFR mutation and treatment efficacy of EGFR-TKIs in Chinese patients with non-small cell lung cancer. Oncotarget. 2017;8:25046-54.

20. Schmid S, Gautschi O, Rothschild S, et al. Clinical outcome of ALK-positive non-small cell lung cancer (NSCLC) patients with de novo EGFR or KRAS comutations receiving tyrosine kinase inhibitors (TKIs). J Thorac Oncol. 2017;12: $681-8$.

\section{Publisher's Note}

Springer Nature remains neutral with regard to jurisdictional claims in published maps and institutional affiliations.
Ready to submit your research? Choose BMC and benefit from:

- fast, convenient online submission

- thorough peer review by experienced researchers in your field

- rapid publication on acceptance

- support for research data, including large and complex data types

- gold Open Access which fosters wider collaboration and increased citations

- maximum visibility for your research: over $100 \mathrm{M}$ website views per year

At BMC, research is always in progress.

Learn more biomedcentral.com/submissions 